\title{
Moderating Effects on Residents' Willingness in Waste Sorting to Improve Waste Handling in Dammam City, Saudi Arabia
}

\author{
Ossama Labib ${ }^{1,2, *(D)}$, Latifah Manaf ${ }^{1}$, Amir Hamzah Sharaai ${ }^{3}$ and Siti Sarah Mohamad Zaid ${ }^{1}$ \\ 1 Department of Environmental Sciences, College of Environmental Studies, University Putra Malaysia, \\ Seri Kembangan, Selangor 43400, Malaysia; latifahmanaf@upm.edu.my (L.M.); \\ mz_sarah@upm.edu.my (S.S.M.Z.) \\ 2 Department of Environmental Health, College of Public Health, Imam Abdulrahman Bin Faisal University, \\ Dammam 31441, Saudi Arabia \\ 3 Department of Environmental Management, College of Environmental Studies, University Putra Malaysia, \\ Seri Kembangan, Selangor 43400, Malaysia; amirsharaai@upm.edu.my \\ * Correspondence: olabib@iau.edu.sa
}

Citation: Labib, O.; Manaf, L.;

Sharaai, A.H.; Zaid, S.S.M.

Moderating Effects on Residents' Willingness in Waste Sorting to Improve Waste Handling in Dammam City, Saudi Arabia. Recycling 2021, 6, 24. https://doi.org/10.3390/ recycling6020024

Academic Editor: Giovanni De Feo

Received: 4 March 2021

Accepted: 22 March 2021

Published: 6 April 2021

Publisher's Note: MDPI stays neutral with regard to jurisdictional claims in published maps and institutional affiliations.

Copyright: (c) 2021 by the authors. Licensee MDPI, Basel, Switzerland. This article is an open access article distributed under the terms and conditions of the Creative Commons Attribution (CC BY) license (https:/ / creativecommons.org/licenses/by/ $4.0 /)$.
Abstract: While the total amount of municipal solid waste (MSW) in Dammam city was about 13 million tons in 2013, it is expected to reach about 18.4 million tons in 2025. Although the main problem in Dammam city is an increase in solid waste production without any formal treatment except landfilling, the lack of waste segregation greatly affects the residents' handling practices of solid waste due to incorrect disposing practices. The objective of this study explored the possibility of Dammam residents' participation in sorting and recycling to improve MSW handling and to measure the influence of psychological factors which affecting residents' willingness to participate in waste handling regarding socioeconomic levels and moderating effects. This study also examined various respondents' perspectives on sorting and recycling sustainable waste and the handling of waste generation. This study covered most Dammam communities, with a gender distribution of $56 \%$ males and $44 \%$ females and the monthly income ranging from SR700 to SR12,000. The descriptive analysis showed that of the 450 participants, $170(37.8 \%)$ were in the middle-income levels, $199(44.2 \%)$ were in the high-income levels and $81(18 \%)$ were in the lowincome levels. The moderating effect of income was observed between attitude and willingness to sort and recycle waste in the low-income levels and high-income levels groups. Additionally, an association was found between market incentives and willingness to sort and recycle waste in the low-income levels and high-income levels groups. The gender status of the participants had a moderating effect on the relationship between market incentives and willingness to sort and recycle waste in males and females. Additionally, the moderating effect of social influence on households' willingness to sort and recycle waste was moderated by gender in males and females.

Keywords: socio-psychological factors; sorting and recycling willingness; moderating effect; Dammam

\section{Introduction}

Municipal solid wastes (MSWs) are generated from several sources in Saudi Arabia, with more than $80 \%$ concentrated in different urban areas. The waste generation is concentrated in the three largest cities in Saudi Arabia (Riyadh, Jeddah and Dammam), each with different physical characteristics. Many countries have moved from waste landfilling to energy recovery, using it as a fuel because it is economically important [1]. Therefore, the Saudi Arabian government has channeled its direction towards minimizing solid waste disposal in landfilling by using waste management characterized by sorting and recycling [2-4]. In Dammam city, the government faces a big strain due to rapid increases in population growth, necessitating increases in municipal solid wastes. The total amount of municipal waste produced in 2005 was estimated to be 10.4 million tons as municipal waste estimated production (MEP, 2005) and about 13 million tons in 2013 [5]. The amount of 
waste was 1093 million tons/per capita/per year, and it is expected to reach about 18.4 million tons in 2025 [6,7]. Additionally, in Dammam city, the only active informal sector is derived from waste sorting and recycling materials such as metals, papers and plastic from different sources, which is highly economically useful; the recycling rate ranged from $10.5 \%$ to $15.5 \%$ [7]. Consequently, sustainable waste handling, including sorting and recycling activities among residents, was suggested. Thus, socio-psychological and external variables can be used to understand solid waste management behavior instead of landfilling in Abqaiq city [8-11].

A strong commitment and unflinching public support by the government is necessary to achieve the successful implementation of a sustainable waste management strategy in Saudi Arabia. This can be achieved by ensuring strong legislation, creating awareness, providing financial support, introducing modern technologies and encouraging residents' participation in waste sorting and recycling, which will significantly help transform Saudi Arabia into a "green" country [7]. Solid waste management primarily aims to eliminate or minimize the negative impacts of waste materials on human health and the environment to encourage economic development and create a better quality of life [12,13]. These aims can be achieved through internal incentives, such as socio-psychological factors, and should be considered an effective means to increase long-term participation in waste sorting and recycling to create proper awareness among the people and enhance their actions for successful waste segregation and recycling goals, as well as to increase positive changes in people's attitudes and behaviors, depending on differences in the socio-psychological backgrounds of the individual, which influence their decisions on whether to participate in waste sorting and recycling activities [14-16]. Therefore, much effort is required to motivate and enlighten people to understand and appreciate the importance of responsible and sustainable waste management practices and to manage their wastes sustainably by sorting waste at its source and recycling it $[17,18]$. Previous studies on household solid waste recycling primarily focused on three aspects of recycling: determinants of waste recycling behaviors, efficiency of waste recycling schemes and the partnerships between formal and informal recycling sectors, with the majority focusing on the effect of psychological factors on recycling behaviors such as attitude, awareness and perceived controls, which were reported to significantly affect residents' willingness to participate in waste sorting and recycling $[19,20]$.

The research questions examined in our study which aim to assist in finding a solution to the problems related to solid waste handling and better participation of the population are the following:

1. What are the effects of psychological factors on residents' willingness to participate in sustainable waste handling in Dammam city?

2. What are the factors that significantly predict the willingness to handle sustainable waste at different income levels in Dammam city?

3. What are the appropriate moderating factors on residents' willingness to participate in sustainable handling practices in Dammam city?

4. Do gender and income levels have moderating effects on residents' willingness to participate in sustainable waste handling in Dammam city?

\section{Literature Review}

Solid waste management is the process of waste collection and treatment of solid waste; its main objective is either eliminating or minimizing the negative impacts of waste materials on human health and the environment to encourage economic development and create a superior quality of life [7]. Saudi Arabia has experienced a rapidly growing population and increased urbanization and industrialization that has led to a high generation of solid waste and, of course, challenges in managing solid waste. This problem has become alarming, especially in cities such as Dammam city, in which landfilling is the primary method of solid waste management [7]. Moreover, the rapid population growth in Dammam has led to increasing solid waste generation. The literature on household solid 
waste recycling has focused mainly on three aspects of recycling: [1] the waste recycling behavior determinants, [2] the efficiency of waste recycling schemes and [3] the partnerships between formal and informal recycling sectors, with most focusing on the effects of psychological (internal) factors on recycling behavior [7,18].

This study proposed a model of a conceptual framework representing the relationship between internal/psychological factors (attitude, awareness and perceived behavioral control), external factors (social influence, market incentives and government facilitators) and residents' sustainable waste handling practices (waste sorting and recycling).

Figure 1 illustrates these relationships between psychological, external factors and sustainable waste handling practices.

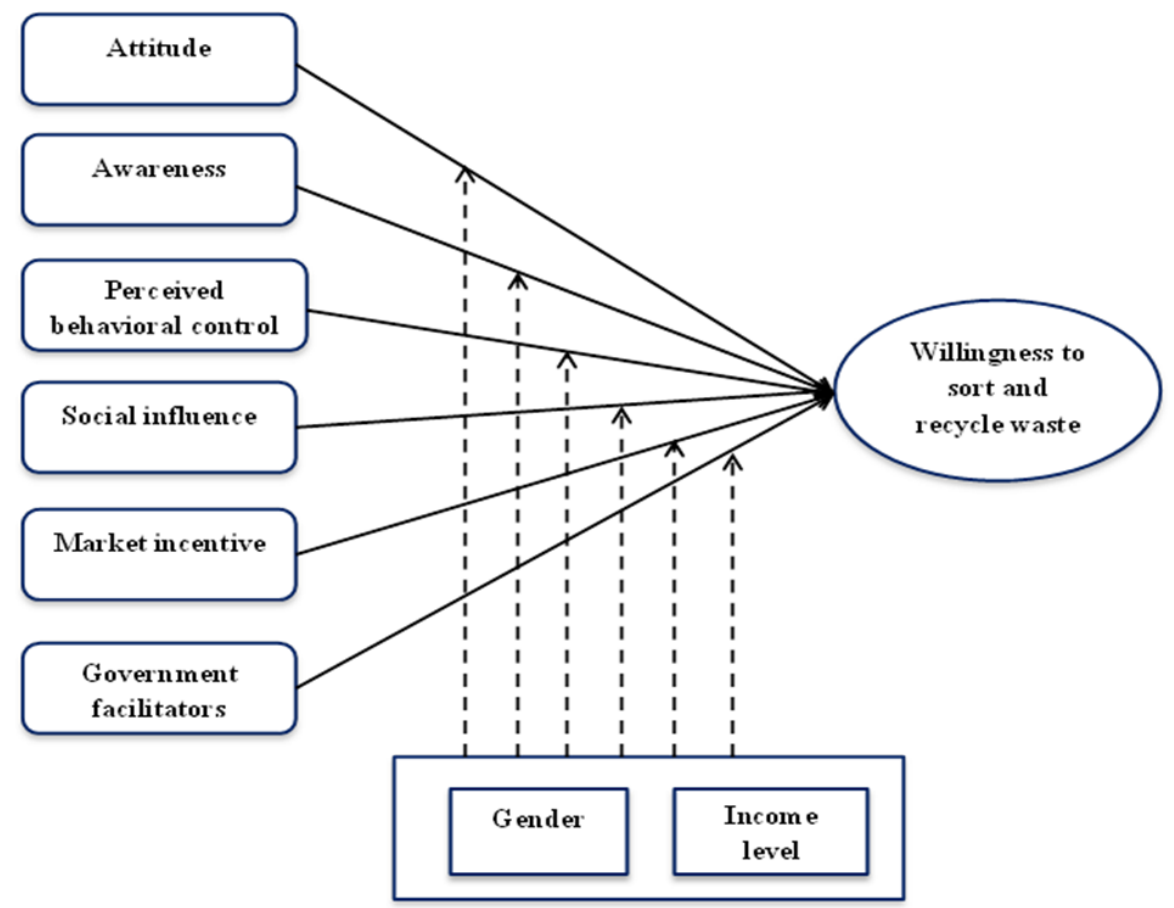

Figure 1. Conceptual framework of the study.

From the conceptual framework, this study focuses on the self-reported residents' sustainable waste handling practices. The findings from previous studies on the sociopsychological determinants of household environmental behavior are the basis for the present study. Studies on waste management behavior, and more specifically waste separation and recycling behavior, formed the basis of this study [21-24]. This study focused on the following variables: attitude, perceived behavioral control, awareness, social influence, market incentives, government facilitators (as independent variables), willingness/intention (as independent variables), income level and gender (as moderating variables).

Determinants of waste recycling behaviors include internal factors, such as attitudes, awareness and perceived control, which were reported to affect residents' willingness to significantly participate in waste sorting and recycling $[25,26]$. While few studies have investigated the effect of external factors in influencing recycling behavior, a limited amount of studies have investigated the combined effects of internal (psychological) and external factors on residents' waste sorting and recycling practices in a single mode [11].

\section{Problem Statement}

The main problem in Dammam city is that solid waste segregation is voluntary for residents and lacks guidelines or regulations; thus, a lack of waste segregation greatly affects the residents' handling practices of solid waste as they incorrectly dispose of it. Thus, solid waste handling by the residents of Dammam city remains in its infancy, although 
sorting and recycling are gaining increased attention $[27,28]$. Although the degree or level of residents' waste sorting and recycling practices have not been investigated in Dammam city, and the residents do not generally participate in sustainable waste handling because the authorities of Saudi Arabia have not established an applicable program of waste handling $[8,9]$, they might be ready to participate in waste handling for useful purposes such as sustainable waste handling instead of merely disposing of waste $[10,11]$. Therefore, we proposed this study in order to enhance the understanding of the sociopsychological and external predictors of residents' willingness to participate in waste sorting and recycling and to also help the authorities in developing policies to support the promotion of waste sorting and recycling.

\section{Scope of the Study}

This study focused on exploring the level of residents' waste sorting and recycling practices because it has not been investigated or understood in Dammam city; additionally, the socio-psychological and external factors regarding waste sorting of the residents of Dammam city are unclear. One can predict residents' sustainable waste handling practices, such as sorting and recycling, by considering existing studies which predict waste management behavior in other countries [8,9]. Not only this, but this study also focused on the moderating effect of demographic factors, such as gender and income levels, on residents' willingness to participate in sustainable handling practices in Dammam city. The results of this study would help the authorities to develop policies to support the promotion of waste sorting and recycling as well as helping to enhance the understanding of the socio-psychological and external predictors of residents' willingness to participate in waste sorting and recycling.

In Dammam city, the solid waste generation is 1,093,000 tons per year according to a population of 603,000, and the most prevalent percentage of solid waste in Saudi Arabia is plastic waste. Nearly $15-20 \%$ of total plastic waste production is recycled by sorting, while plastic waste disposal in landfills creates environmental and operational burdens in the landfill, attributed to a slow degradation process. Here, the pyrolysis process can be used to treat plastic waste materials and generate power, such as fuel oil, and valuable products, such as coal $[29,30]$.

\section{Methodology}

This section describes the research design and adopts a quantitative method based on the objectives and research questions using a questionnaire survey in Dammam.

\subsection{Study Area}

Dammam is the capital of the Eastern Province of Saudi Arabia. This city contains the judicial and administrative bodies and many government departments in the Eastern province. Dammam is the sixth largest city in Saudi Arabia, after Riyadh, Jeddah, Mecca, Medina and Taif, making it the Eastern Province's largest city in the country. In 2012, the population of the Dammam metropolitan area was estimated at 4,140,000, whereas Dammam city has a population of more than 1.7 million, with a growth rate of $12 \%$ per year. This growth rate is seen as the fastest not only in Saudi Arabia but also among the Gulf Cooperation Council. Greater Dammam emerged as the fourth largest area in both population and size in the Gulf Cooperation Council (GCC) in 2016 [31-33].

The major method for waste disposal in Dammam is landfilling and combustion, with little waste being converted for compost. However, the dominant practices for waste disposal are unsustainable as they pose serious dangers to the environment. The improper waste disposal without proper treatment can cause dangers such as pollution of ground and surface waters [34-36]. 


\subsection{Study Survey}

The target survey concentrated on the population area of Dammam city, including all residents. The accessible population comprises residents from different income groups of the city. The number of households in the Dammam metropolitan area is estimated at 331,000, distributed in 75 neighborhoods in the East, Middle and West districts, comprising mostly independent villas and low-rise residential buildings [33]. Figure 2 shows the distribution of different districts in different regions (East, Middle and West) in Dammam city.

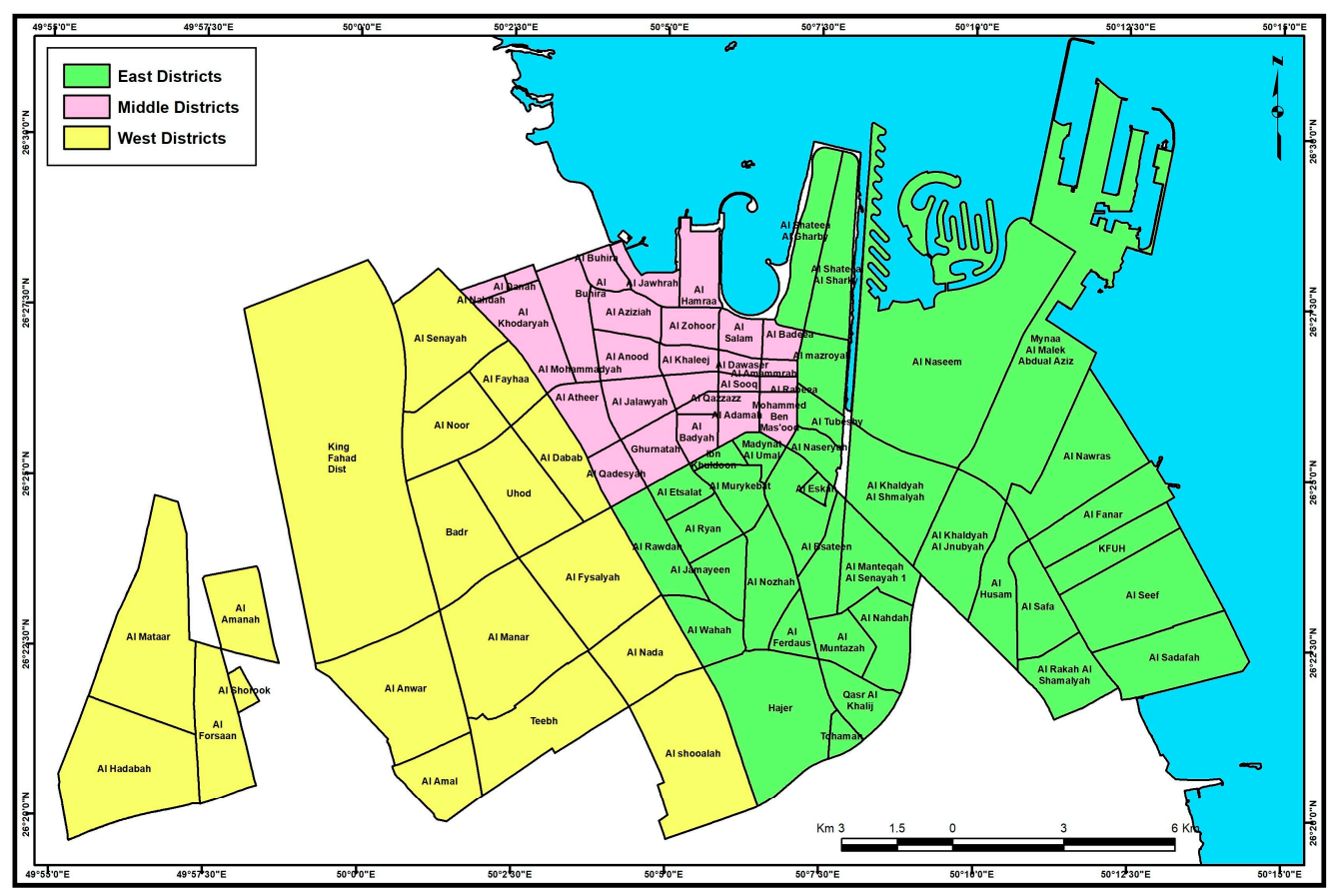

Figure 2. Distribution of different districts in Dammam city by neighborhood. Source: Imam Abdulrahman Bin Faisal University, College of Arts and Department of Geography.

\subsection{Questionnaire Survey}

The questionnaire survey was divided into three sections.

\subsubsection{Section 1: Demographic Questions}

This section included district and area of Dammam, which included residence, gender, age, marital status, monthly household income level, household size, educational level and respondent occupation [37]. Figure 3 shows the distribution of the different district income levels (high, middle and low levels) in different regions (East, Middle and West) in Dammam city.

5.3.2. Section 2: Attitudes, Awareness, Perceived Behavioral Control and Willingness/Intention

Attitudes

This included statements of waste sorting and recycling to examine the importance of waste sorting by contacting residents of Dammam whose household wastes have been sorted and recycled, to ascertain whether they were interested in waste sorting or considered waste sorting sensible and rewarding and whether they thought waste sorting conserved energy [38].

\section{Awareness}

This significantly predicts a person's willingness to participate in waste sorting and recycling to ascertain whether he/she perceived that the outcome of waste recycling would be useful to his/her environment. This section includes statements regarding waste sorting 
and recycling, along with questions about the impacts of waste sorting to prevent odor induced by waste accumulation; thus, it is important to reduce waste disposal and the raw materials' cost, thereby decreasing the health risks of waste [39].

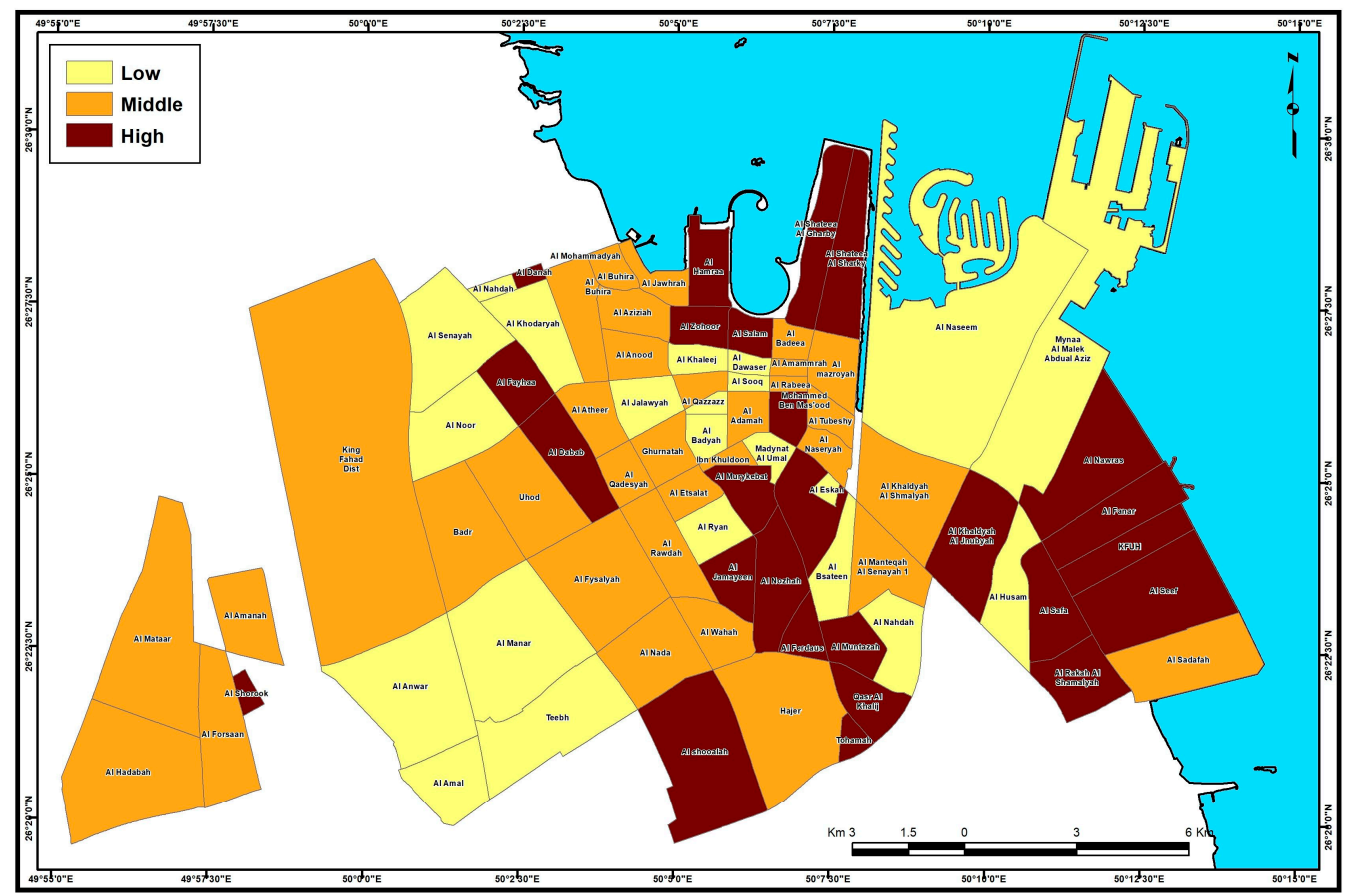

Figure 3. Map of income distribution by neighborhood in the districts. Source: Imam Abdulrahman Bin Faisal University, College of Arts and Department of Geography.

\section{Perceived Behavioral Control}

This includes statements regarding the integration of waste sorting and recycling, household intentions to participate regularly in collection services, satisfaction and participation in waste sorting by sharing with local authorities, making more efforts in household waste sorting through public participation in the sorting process, making recycling more efficient, feeling that household waste sorting was good, intending to apply the environmental program to sort the waste from the source in Dammam and intending to sort household waste as much as possible every day [40].

\subsubsection{Section 3: Social Influence, Market Incentives, Government Facilitators, Age and Income Levels \\ Social Influence}

Social influence is related to listening to the advice of family members, neighbors and friends about waste recycling. Statements included whether they would listen to family, friends, neighbors; the role of government support and participation in innovative programs; sharing in advice regarding household waste handling if possible; supporting governments to help implement waste handling, etc.

\section{Market Incentives}

Market incentives include supporting the government in performing waste recycling and sorting. Statements include satisfaction with incentives, whether these incentives improved the relationship with waste collectors, economic benefits and environmental regulations, among others [41].

\section{Governmental Facilitators}

The support of the waste handling services by the government is important to improve waste recycling and sorting. Statements include those concerning penalties, the provision 
of waste handling training programs, environmental legislation and whether government support would increase the participation of residents in waste handling, among others [41].

Gender

The results of studies examining the impact of gender on environmental behaviors have been mixed. Some previous studies have reported no relationship between gender and environmentally friendly behaviors (EFBs) [42-44].

Conversely, some recent studies have found that women usually participate in programs related to the environment more than men. Han and Hansen (2012) found that females showed a higher willingness to perform pro-environmental behaviors (PEBs) and felt that a lack of participation in environmental programs would negatively impact them, the environment and society considerably more than it would males [45].

One interesting perspective is that of Fisher et al. (2012), which revealed that most research that reported women with stronger PEBs was conducted after 2010. They argued that recently the culture had been shifting towards women participating in EFBs more than men, which could be because of the mixed results and the absence of studies in countries in the Arabian Gulf, such as Saudi Arabia. Additional studies are required to further confirm the role of gender in influencing PEBs, particularly waste sorting and recycling practices. This study included gender as a moderating variable to determine its effect on the associations between the predictor variables and residents' willingness to participate in waste sorting and recycling [46].

Income Level

A handful of studies have examined the impact of income on PEBs. Fisher et al. (2012) reviewed 23 studies that included income in determining its relationship with various EFBs. Their findings showed that of the 23 studies, no significant differences were observed between different income groups based on their intention to participate in EFBs. Three studies established that higher incomes were associated with EFBs, and two studies established that lower incomes were more associated with these behaviors [46].

This study focused on self-reports of residents' sustainable waste handling practices and considered the findings from previous studies on the socio-psychological determinants of household environmental behaviors. Studies on waste management behaviors, and more specifically waste separation and recycling behaviors, were foundational to this study [47-49]. This study considered the following variables: attitudes, perceived behavioral controls, awareness, social influence, market incentives, government facilitators (as independent variables), willingness/intention (as the independent variables), income level and gender (as the moderating variables).

\subsubsection{Moderating Analysis}

Moderators are variables that identify the conditions under which a given independent variable (predictor) is associated with a dependent variable (outcome). Similarly, the moderators indicate when a predictor and outcome are related. Moderation explains an interaction effect in which the inclusion of a moderator alters the magnitude or direction of the association between the predictor and the outcome. Figure 4 explains the interaction effect of the moderator on the independent variables (moderating effect).

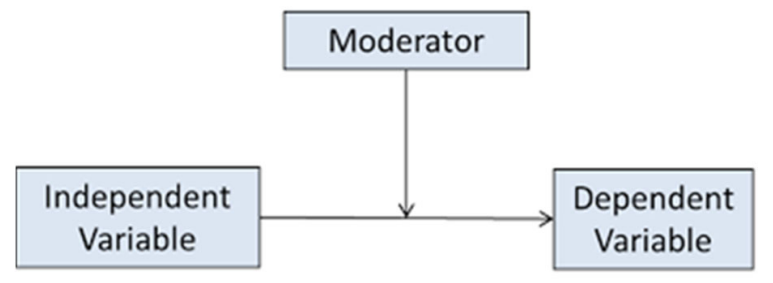

Figure 4. Independent moderators (moderating effect). 
A moderation effect can appear in different forms, as follows:

$>$ Enhancing, where increasing the moderator would increase the effect of the predictor on the outcome;

$>$ Buffering, where increasing the moderator would decrease the effect of the predictor on the outcome; or

$>$ Antagonistic, where increasing the moderator reverses the effect of the predictor on the outcome [50].

New models were developed for each moderator to test the moderating effect of these moderator variables after the independent moderator was introduced in this model. The R2 (variance) of the model increased to 64 , and the model fitted the indices. Conventionally, relative $\chi^{2}$ should be $<5$, while the adjusted goodness fit index (AGFI), goodness fit index (GFI), comparative fit index (CFI), Bentler-Bonett normed fit index (NFI), incremental fit index (IFI) and Tucker-Lewis index (TLI) must be $>0.9$ [17], and Root Mean Square Residual (RMR) and Root Mean Square Error of Approximation (RMSEA) should be $<0.08$ [51]. A model is said to be fit when it meets any three or four of the fit indices [52]. Thus, based on this, the structural model for testing the moderating effect in this study fits the data.

This study used a multigroup analysis technique to perform the moderating analysis. Samah (2016) reported that two steps could be followed to perform a moderating test: (1) determining the presence of the moderator on the overall model and then (2) determining the effect of the moderator on the individual paths in the structural model [53].

To determine the effect of the moderator, income level and gender on the overall model, the unconstrained model (variant-group model) was compared with the measurement residual model (invariant-group model) based on their goodness-of-fit indices, as Samah (2016) recommended. If the unconstrained model has a smaller Chi-square and degree of freedom compared with the residual measurement model, then the unconstrained model outperforms the residual measurement model, implying that there is a moderating effect on the overall model [53].

\section{Results and Discussion}

\subsection{Perspectives on the Willingness to Engage in Sustainable Waste Handling Practices}

This section specifically discusses the perspectives of households regarding sustainable solid waste handling of residents for recycling practices in distinct aspects. The following subsections show the descriptive discussions of the results obtained and the analytical discussions.

\section{Demographic Characteristics}

The description of the socioeconomic variables of the respondents included their gender, age, marital status, level of education, employment status, household size and household income. Hence, Table 1 summarizes these demographic variables.

From Table 1, the economic profile of the respondents covered most Dammam communities, with gender distribution of $56 \%$ males and $44 \%$ females. The age group ranged from 18 to 68 , and the marital status distribution was $54.7 \%$ married, $44.7 \%$ single, $0.44 \%$ divorced and $0.22 \%$ widower. The employment distribution was $54.2 \%$ government employees, $16.9 \%$ private employees, $23.3 \%$ unemployed, $2.22 \%$ self-employed, $2.9 \%$ housewives and $0.44 \%$ pensioners. Finally, the household monthly income ranged from SR700 to SR12,000, distributed as $21.1 \%$ below SR1000, 38.9\% (SR1000-SR5000) and 40\% exceeding SR5000.

\subsection{Levels of Variables of the Study in Sorting and Recycling}

This assesses the levels of residents' attitudes, awareness, perceived control, willingness and external factors (social influence, market incentives and government facilitators) concerning sustainable solid waste handling (sorting and recycling) in Dammam city. The respondents' responses to all the variables were categorized into three levels. The criterion used in setting up the cut-off points for the categories was based on the score range. Here, 
the respondents' level for each variable was categorized into high, moderate and low levels. Frequencies, percentages, means and standard deviations were also provided for each variable. Table 2 summarizes the participants' levels for the study variables.

Table 1. Socioeconomic profile of the respondents $(n=450)$.

\begin{tabular}{|c|c|c|c|c|}
\hline Variable & Frequency & Percentage & Min. & Max. \\
\hline \multicolumn{5}{|c|}{ Gender: } \\
\hline Male & 252 & 56 & & \\
\hline Female & 198 & 44 & & \\
\hline \multicolumn{3}{|c|}{ Age Group: } & 18 & 68 \\
\hline $18-29$ & 129 & 28.7 & & \\
\hline $30-39$ & 71 & 15.8 & & \\
\hline $40-49$ & 209 & 46.4 & & \\
\hline $50-59$ & 33 & 7.30 & & \\
\hline 60 above & 8 & 1.80 & & \\
\hline \multicolumn{5}{|c|}{ Marital Status: } \\
\hline Married & 246 & 54.7 & & \\
\hline Single & 201 & 44.7 & & \\
\hline Divorced & 2 & 0.44 & & \\
\hline Other & 1 & 0.22 & & \\
\hline \multicolumn{5}{|c|}{ Educational Level: } \\
\hline Primary & 2 & 0.44 & & \\
\hline Secondary & 15 & 3.33 & & \\
\hline Diploma & - & - & & \\
\hline College degree & 336 & 74.7 & & \\
\hline MSc./PhD. & 97 & 21.5 & & \\
\hline \multicolumn{5}{|c|}{ Employment: } \\
\hline Govt.-Employed & 244 & 54.2 & & \\
\hline Private-Employed & 76 & 16.9 & & \\
\hline Self-Employed & 10 & 2.22 & & \\
\hline Unemployed & 105 & 23.3 & & \\
\hline Housewife & 13 & 2.90 & & \\
\hline Pensioner & 2 & 0.44 & & \\
\hline \multicolumn{3}{|c|}{ Household Size: } & 2 & 16 \\
\hline 1-5 Persons & 238 & 52.9 & & \\
\hline 6-10 Persons & 195 & 43.3 & & \\
\hline 11-15 Persons & 17 & 3.80 & & \\
\hline 16 and Above & - & - & & \\
\hline \multicolumn{3}{|c|}{ Household Monthly Income: } & SR700 & SR12,000 \\
\hline Less than SR1000 & 95 & 21.1 & & \\
\hline SR1000-SR5000 & 180 & 40 & & \\
\hline More than SR5000 & 175 & 38.9 & & \\
\hline
\end{tabular}


Table 2. Summarizing the participants' levels for the study variables.

\begin{tabular}{|c|c|c|c|c|c|c|}
\hline \multirow{3}{*}{ Variable } & \multicolumn{6}{|c|}{ Levels/Frequency $(\mathrm{N})$ and Percentage (\%) } \\
\hline & \multicolumn{2}{|c|}{ Low } & \multicolumn{2}{|c|}{ Middle } & \multicolumn{2}{|c|}{ High } \\
\hline & $(\mathrm{N})$ & $(\%)$ & (N) & $(\%)$ & (N) & $(\%)$ \\
\hline $\operatorname{ATT}(S)$ & 42 & 9.33 & 151 & 33.6 & 257 & 57.1 \\
\hline $\operatorname{ATT}(\mathrm{R})$ & 40 & 8.9 & 162 & 36 & 248 & 55.1 \\
\hline AWNS (S) & 41 & 9.11 & 198 & 44.0 & 211 & 46.9 \\
\hline AWNS (R) & 37 & 8.22 & 201 & 44.7 & 212 & 47.1 \\
\hline $\mathrm{PBC}(S)$ & 131 & 29.1 & 215 & 47.8 & 104 & 23.1 \\
\hline $\mathrm{PBC}(\mathrm{R})$ & 120 & 26.7 & 223 & 49.6 & 107 & 23.8 \\
\hline WILL (S) & 76 & 16.9 & 122 & 27.1 & 252 & 56 \\
\hline WILL (R) & 69 & 15.3 & 133 & 29.6 & 248 & 55.1 \\
\hline MI & 81 & 18.0 & 170 & 37.8 & 199 & 44.2 \\
\hline SI & 99 & 22 & 121 & 26.9 & 230 & 51.1 \\
\hline GF & 84 & 18.7 & 107 & 23.7 & 259 & 57.6 \\
\hline
\end{tabular}

Note : ATT = Attitude; AWNS = Awareness; PBC = Perceived behavioral control; WILL = Willingness; MI = Market incentive; $\mathrm{SI}=$ Social influence; $\mathrm{G}=$ Government facilitators; $(\mathrm{S})=$ Sorting; and $(\mathrm{R})=$ Recycling.

Table 2 shows that 40 respondents (8.9\%) were in the low levels, 162 (36\%) were in the middle levels and 248 (55.1\%) were in the high levels of attitude towards waste recycling. This revealed that a high percentage of participants (57.1\%) and (55.1\%) claimed having a high positive attitude towards waste sorting and recycling, respectively. Additionally, 41 participants representing (9.11\%) were in the low levels, 198 (44\%) were in the moderate levels and $211(46.9 \%)$ were in the high levels of awareness towards waste sorting. Additionally, 37 respondents $(8.22 \%)$ were in the low levels, $201(44.7 \%)$ were in the moderate levels and $212(47.1 \%)$ were in the high levels of awareness towards waste recycling. Further, 131 participants (29.1\%) were in the low levels, 215 (47.8\%) were in the middle levels and $104(23.1 \%)$ were in the high levels of perceived behavioral control towards waste sorting. Similarly, 120 participants $(26.7 \%)$ were in the low levels, $223(49.6 \%)$ in the middle levels and 107 (23.8\%) in the high levels of perceived behavioral control towards waste recycling. The descriptive analysis of the study revealed that of 450 participants, $76(16.9 \%)$ were in the low levels, $122(27.1 \%)$ in the middle levels and $252(56 \%)$ in the high levels of willingness to participate in waste sorting, while 69 households (15.3\%) were in the low levels, 133 (29.6\%) in the middle levels and 248 (55.1\%) in the high levels of willingness to participate in waste recycling. This result suggests that a high percentage of households were willing to participate in waste sorting and recycling.

The descriptive analysis of the research indicated that of 450 participants, 170 households representing (37.8\%) were in the middle levels, $199(44.2 \%)$ in the high levels and $81(18 \%)$ in the low levels. This showed that a high percentage of households felt that market incentives influenced their willingness to participate in waste sorting and recycling. The descriptive analysis showed that of the 450 households, 99 participants (22\%) were in the low levels, 121 (26.9\%) in the middle levels and 230 (51.1\%) in the high level. This indicates that most participants (57.1\%) were in the high level of the social influence category. This suggests that respondents thought that the important people around them had high expectations for them to engage in waste sorting and recycling. Additionally, 84 participants $(18.7 \%)$ were in the low levels, $107(23.7 \%)$ in the middle levels and 259 $(57.6 \%)$ in the high levels. This shows that a high percentage of the participants $(57.6 \%)$ scored high regarding government facilitators, indicating that government commitment to providing adequate facilities would greatly influence their willingness to participate in waste sorting and recycling.

\subsection{Analysis of the Moderating Effects of Income and Gender}

The moderating effect aimed to examine the moderating effect of demographic factors (gender and income level) on residents' willingness to participate in sustainable waste handling practices in Dammam city. A moderator is a variable that alters the relationship 
between the predictor variable(s) and an outcome variable. This study used two demographic variables (income level and gender) as the moderators to test their moderating effect on the causal relationship among all the independent variables and households willingness to sort and recycle waste in Dammam city. For this study, household income measures the income of household heads: salary per month, average monthly income, retirement income and income from investments and other businesses. The variable was split into two groups (high income and low income), whereas gender refers to the variations between males and females.

This study used a multigroup analysis technique to perform the moderating analysis. Samah (2016) reported that two steps are followed to perform a moderating test: (1) determining the presence of the moderator on the overall model and (2) determining the impact of the moderator on the individual paths in the structural model [53].

To determine the effect of the moderator, income level, and gender on the overall model, the unconstrained model (variant-group model) was compared with the measurement residual model (invariant-group model) based on their goodness-of-fit indices, as recommended by Samah (2016). If the unconstrained model has a smaller Chi-square and degree of freedom compared with the measurement residual model, then the unconstrained model outperforms the residual measurement model, implying a moderating effect on the overall model [53].

The comparison of the two models for the two moderators was performed as follows:

$>$ For Income Level:

Unconstrained model: $\chi^{2}(\mathrm{CMIN})=1878.439, \mathrm{df}=875, p=0.000$

Measurement of residuals model: $\chi^{2}(\mathrm{CMIN})=2245.700, \mathrm{df}=958, p=0.000$

$\Delta \chi^{2}(\mathrm{CMIN})=(2245.700-1878.439) ; \Delta \mathrm{df}=(958-875) ; p=0.000$

$\Delta \chi^{2}(\mathrm{CMIN})=367.261 \Delta \mathrm{df}=83 ; p=0.000$

$>$ For Gender:

Unconstrained model: $\chi^{2}(\mathrm{CMIN})=1887.523, \mathrm{df}=812, p=0.000$

Measurement of residuals model: $\chi^{2}(\mathrm{CMIN})=2292.800, \mathrm{df}=965, p=0.000$

$\Delta \chi^{2}(\mathrm{CMIN})=(2292.800-1887.523) ; \Delta \mathrm{df}=(965-812) ; p=0.000$

$\Delta \chi^{2}(\mathrm{CMIN})=405.277 \Delta \mathrm{df}=153 ; p=0.000$

Considering the above results, the measurement of the residual Chi-square exceeded the unconstrained Chi-square for both income level and gender moderators. Therefore, we concluded that income and gender had a moderating influence on the model. Having found that the gender and income levels of the households had a moderating influence on the overall model, testing their moderating effects on the individual paths followed. This was performed using different decision criteria. This study adopted the criterion suggested by Hair et al. (2010), which was based on the value of the standardized path coefficient (Beta) from the Analysis of a Moment Structures AMOS text output. As per Hair [54], the association between independent and dependent variables is moderated by a moderator if:

$>$ Beta $(\beta)$ for Group 1 is significant, while for Group 2 it is non-significant; or,

$>\operatorname{Beta}(\beta)$ for both groups (Groups 1 and 2 ) are significant. Nevertheless, one is positive and the other is negative.

After running the multigroup analysis built upon the above-stated criteria for both moderators, income level and gender, the result of the moderating tests shows that of the six paths, three were moderated by income level, whereas two were moderated by gender. Those moderated by income level comprised attitude-willingness to sort and recycle (low income $(\beta=0.3497, p=0.000)$ and high income $(\beta=-0.1044, p=0.363))$, market incentivewillingness to sort and recycle (low income $(\beta=0.0439, p=0.01425)$ and high income $(\beta=0.2583, p=0.0766))$ and government facilitators-willingness to sort and recycle (low income $(\beta=0.0451, p=0.4762)$ and high income $(\beta=0.4634, p=0.0012))$. The other three paths: awareness-willingness to sort and recycle (low income $(\beta=0.00593, p=0.0718$ ) 
and high income $(\beta=0.0731, p=0.2456))$, perceived behavioral control - willingness to sort and recycle (low income $(\beta=0.0267, p=0.244)$ and high income $(\beta=0.0189, p=0.1521)$ ) and social influence-willingness to sort and recycle (low income $(\beta=0.0973, p=0.000)$ and high income $(\beta=0.4387, p=0.0187)$ ), were not moderated by household income (Table 3 ).

Table 3. Results of moderation test of income level on the relationship between predictors and willingness to sort and recycle.

\begin{tabular}{|c|c|c|c|c|}
\hline Construct & $\begin{array}{l}\text { Observations in } \\
\text { Each Group }\end{array}$ & $\begin{array}{l}\text { Unstandardized Regression } \\
\text { Weight Estimate (B) }\end{array}$ & $\begin{array}{l}\text { Standardized Regression } \\
\text { Weight Estimate }(\beta)\end{array}$ & $p$-Value \\
\hline \multicolumn{5}{|c|}{ Attitude towards sorting and recycling } \\
\hline Low income & 95 & 0.6104 & 0.3497 & $0.000 * *$ \\
\hline High income & 175 & -0.0905 & -0.1044 & 0.3638 \\
\hline \multicolumn{5}{|c|}{ Awareness of sorting and recycling } \\
\hline Low income & 95 & 0.01484 & 0.00593 & 0.0718 \\
\hline High income & 175 & 0.08207 & 0.073017 & 0.2456 \\
\hline \multicolumn{5}{|c|}{ Perceived behavioral control regarding sorting and recycling } \\
\hline Low income & 95 & 0.02672 & 0.0267 & 0.2440 \\
\hline High income & 175 & 0.0152 & 0.0189 & 0.1521 \\
\hline \multicolumn{5}{|c|}{ Market incentive regarding sorting and recycling } \\
\hline Low income & 95 & 0.0439 & 0.0439 & 0.0143 \\
\hline High income & 175 & 0.254 & 0.2583 & 0.0766 \\
\hline \multicolumn{5}{|c|}{ Social influence on sorting and recycling } \\
\hline Low income & 95 & 0.1543 & 0.0973 & $0.000 * *$ \\
\hline High income & 175 & 0.3478 & 0.4387 & 0.0187 * \\
\hline \multicolumn{5}{|c|}{ Government facilitators regarding sorting and recycling } \\
\hline Low income & 95 & 0.0386 & 0.0451 & 0.2600 \\
\hline High income & 175 & 0.0012 & 0.4634 & 0.0012 \\
\hline
\end{tabular}

* Moderating is significant at the 0.05 level; ${ }^{* *}$ Moderating is significant at the 0.01 level.

The regression paths moderated by gender included market incentive-willingness to sort and recycle (male $(\beta=0.084, p=0.028)$ and female $(\beta=0.418, p=0.129)$ ) and social influence-willingness to sort and recycle (male $(\beta=-0.178, p=0.000)$ and female $(\beta=0.708$, $p=0.041)$ ). The other four paths not moderated by gender were attitude-willingness to sort and recycle (male $(\beta=0.689, p=0.341)$ and female $(\beta=0.193, p=0.606))$, awarenesswillingness to sort and recycle (low income $(\beta=0.031, p=0.481)$ and female $(\beta=0.120$, $p=0.508)$ ), perceived behavioral control—willingness to sort and recycle (male $(\beta=0.028$, $p=0.412)$ and female $(\beta=0.185, p=0.261))$ and government facilitators-willingness to sort and recycle (male $(\beta=0.086, p=0.048)$ and female $(\beta=0.778, p=0.003)$ ) (Table 4$)$.

For testing the moderating effect of income level on individual paths, the following hypotheses were posited and tested.

\subsubsection{Income Levels}

From the moderating analysis results in Table 3 above, a moderating effect of income was observed between attitude and willingness to sort and recycle waste (low income $(\beta=0.3497, p=0.000)$ and high income $(\beta=-0.1044, p=0.3638))$. Thus, this association was supported. Additionally, the income level did not moderate the association between awareness and households' willingness to sort and recycle waste (low income $(\beta=000593$, $p=0.0718)$ and high income $(\beta=0.07301, p=0.2456))$. Therefore, this association was not supported. The regression path between perceived behavioral control and willingness to sort and recycle waste was not moderated by income level (low income $(\beta=0.0267$, 
$p=0.244)$ and high income $(\beta=0.0189, p=0.1521))$. Therefore, this association was not supported. The income status of the households had a moderating effect on the relationship between market incentives and willingness to sort and recycle waste (low income $(\beta=0.0439, p=0.01425)$ and high income $(\beta=0.2583, p=0.0766))$. Therefore, this association was supported. The effect of social influence on households' willingness to sort and recycle waste was not moderated by income level (low income ( $\beta=0.0973, p=0.000$ ) and high income $(\beta=0.4387, p=0.0187))$. Thus, this association was not supported.

Table 4. Results of moderation test of gender on the relationship between predictors and willingness to sort and recycle.

\begin{tabular}{|c|c|c|c|c|}
\hline Constructs & $\begin{array}{l}\text { Observations in } \\
\text { Each Group }\end{array}$ & $\begin{array}{c}\text { Unstandardized Regression } \\
\text { Weight Estimate (B) }\end{array}$ & $\begin{array}{c}\text { Standardized Regression } \\
\text { Weight Estimate }(\beta)\end{array}$ & $p$-Value \\
\hline \multicolumn{5}{|c|}{ Attitude towards sorting and recycling } \\
\hline Male & 252 & 1.019 & 0.689 & 0.341 \\
\hline Female & 198 & 0.160 & 0.193 & 0.606 \\
\hline \multicolumn{5}{|c|}{ Awareness of sorting and recycling } \\
\hline Male & 252 & 0.014 & 0.031 & 0.481 \\
\hline Female & 198 & 0.127 & 0.120 & 0.508 \\
\hline \multicolumn{5}{|c|}{ Perceived behavioral control regarding sorting and recycling } \\
\hline Male & 252 & 0.025 & 0.028 & 0.412 \\
\hline Female & 198 & 0.168 & 0.185 & 0.261 \\
\hline \multicolumn{5}{|c|}{ Market incentive regarding sorting and recycling } \\
\hline Male & 252 & 0.127 & 0.084 & 0.028 * \\
\hline Female & 198 & 0.406 & 0.418 & 0.129 \\
\hline \multicolumn{5}{|c|}{ Social influence on sorting and recycling } \\
\hline Male & 252 & -0.250 & -0.178 & $0.000 * *$ \\
\hline Female & 198 & 0.577 & 0.708 & $0.041 *$ \\
\hline \multicolumn{5}{|c|}{ Government facilitators regarding sorting and recycling } \\
\hline Male & 252 & 0.089 & 0.086 & 0.048 * \\
\hline Female & 198 & 0.499 & 0.778 & $0.003 *$ \\
\hline
\end{tabular}

* Moderating is significant at the 0.05 level; ${ }^{* *}$ Moderating is significant at the 0.01 level.

The regression path between government facilitators and willingness to sort and recycle waste was moderated by income (low income $(\beta=0.0451, p=0.4762)$ and high income $(\beta=0.4634, p=0.0012))$. Therefore, this association was supported.

\subsubsection{Gender}

Similarly, for testing the moderating effect of gender on individual paths, the moderating analysis results in Table 4 above show that a moderating effect of gender was unobserved on the association between attitude and willingness to sort and recycle waste (male $(\beta=0.689, p=0.341)$ and female $(\beta=0.198, p=0.606))$. Thus, this association was not supported.

Additionally, gender did not moderate the association between awareness and households' willingness to sort and recycle waste (male $(\beta=0.031, p=0.481)$ and female $(\beta=0.120$, $p=0.508)$ ). Therefore, this association was not supported. Additionally, a moderating effect was unobserved between perceived behavioral control and willingness to sort and recycle waste, which was not moderated by gender (male $(\beta=0.028, p=0.412)$ and female $(\beta=0.185$, $p=0.261)$ ). Therefore, this association was not supported. Based on the moderating effect, the gender status of the respondents had a moderating effect on the relationship between 
market incentives and willingness to sort and recycle waste (male $(\beta=0.084, p=0.028)$ and female $(\beta=0.418, p=0.129))$. Therefore, this association was supported.

The result of the structural model for moderation analysis in Table 4 above shows that the effect of social influence on households' willingness to sort and recycle waste was moderated by gender (male $(\beta=-0.178, p=0.000)$ and female $(\beta=0.708, p=0.041)$ ). Thus, this association was supported. Additionally, the results of the moderating analysis in Table 4 above indicate that the regression path between government facilitators and willingness to sort and recycle waste was not moderated by gender (male $(\beta=0.086$, $p=0.048)$ and female $(\beta=0.778, p=0.003))$. Therefore, this association was not supported.

This study primarily examined the moderating effect of demographic factors (gender and income level) on residents' willingness to participate in sustainable waste handling practices in Dammam city. The income moderation result shows that the causal relationships between attitude, market incentive, government facilitators and willingness to sort and recycle were moderated by the income level of the households. This means that when the income level of a household increases, the causal relationship between attitudewillingness and market incentive-willingness tends to diminish. That is to say, high-income households may have low willingness towards waste sorting and recycling, especially when recycling facilities and local collections are unavailable. Conversely, low-income households' attitudes may influence their willingness to sort and recycle regardless of recycling facilities' availability. This finding supported the t-test results in objective two. Similarly, the moderating result shows that the causal relationship between government facilitators and willingness to sort and recycle waste was positive and significant for highincome households; however, the same relationship was positive but not significant for low-income households. This suggests that households in the high-income group are motivated by the availability of recycling facilities, which is directly linked to their perceived control. Conversely, households in the low-income group are more concerned about the financial benefits of recycling rather than the recycling facilities. Their low-income status may influence their recycling intention, as indicated in their market incentive, which was significant for low-income but not significant for high-income households. This agrees with Fisher et al. (2012), MacCoun (1998) and Straughan et al. (1999) [46,55,56], in contrast to Arminda and Raposo (2009) and Meyer and Liebe (2010), who reported that higher-income consumers were more likely to perform EFBs $[57,58]$.

Nevertheless, the households' income status did not moderate the relationships between social influence, awareness, perceived behavioral control and willingness to sort and recycle. The relationship between perceived behavioral control and willingness to sort and recycle was not moderated by the income status of the households (low income $(\beta=0.021, p=0.411)$ and high income $(\beta=0.0155, p=0.252))$. One possible explanation is that when households perceived that they had a higher level of control over waste sorting and recycling activities, they were motivated to engage in recycling regardless of their income status. Additionally, the result for gender moderation analysis indicates multigroup effects between males and females. It shows that the regression path of market incentive to willingness to sort and recycle was significant for males but insignificant for females (male $(\beta=0.084, p=0.418)$ and females $(\beta=0.028, p=0.129))$. Similarly, the results revealed that the path coefficient of social influence to willingness to sort and recycle was moderated by gender. The multigroup moderating result for gender shows that social influence had a more significant effect on willingness to sort and recycle in women than men (male $(\beta=-0.178, p=0.000)$ and female $(\beta=0.708, p=0.041))$. Although previous studies have reported that gender was not a significant determinant for willingness to recycle, as Gamba and Oskamp (1994) and Botetzagias, Dima and Malesios (2015) posited, the findings of this study demonstrated that the effect of market incentive and social influence on willingness to sort and recycle waste varies between males and females $[45,59]$. 


\section{Conclusions}

This study focused on exploring the degree or level of residents' waste sorting and recycling practices because this has not previously been investigated in Dammam city, and the only active informal sector is derived from waste sorting and recycling, such as metals, papers and plastic from different sources, which is highly economically useful; the rate of recycling was in the range of 10.5-15.5\%. The target survey concentrated on the population area of Dammam city, including all residents. The households in the Dammam metropolitan area were estimated at 331,000, distributed in 75 neighborhoods in the East, Middle and West districts. Additionally, the profile of the respondents in the various Dammam communities had a gender distribution of $56 \%$ males and $44 \%$ females and the income distribution levels were $21.1 \%$ below SR1000, 38.9\% between SR1000 and SR5000 and $40 \%$ exceeding SR5000.

The scientific benefit of this study is that solid waste management should focus on problems related to the accumulation of solid wastes, which many governments and residential communities may be facing. The benefit and scientific value of the research is that it works to solve the problems arising from the production of solid waste, especially landfilling, which is without any benefit and not profitable, by examining a suitable treatment commensurate with of population increases. Thus, we concentrated in this study on strengthening the psychological awareness of the residents of Dammam.

The descriptive analysis results indicated that of 450 participants, 170 households (representing 37.8\%) were in the middle-income levels, 199 (44.2\%) in the high-income levels and $81(18 \%)$ in the low-income levels. The moderating effect of income was observed between attitude and willingness to sort and recycle in low- and high-income levels, but the income level did not moderate the association between awareness and households' willingness to sort and recycle waste. The regression path between perceived behavioral control and willingness to sort and recycle waste was not moderated by low- and high-income levels. The income status of the households had a moderating effect on the relationship between market incentives and willingness to sort and recycle waste in low- and high-income levels. The effect of social influence on households' willingness to sort and recycle waste was also not moderated by low- and high-income levels. A moderating effect of gender was unobserved on the association between attitude and willingness to sort and recycle waste in males and females. Additionally, gender did not moderate the association between awareness and households' willingness to sort and recycle waste in males and females. The moderating effect was unobserved between perceived behavioral control and willingness to sort and recycle waste, which was not moderated by gender in males in females. Based on the moderating effects, the gender status of the respondents had a moderating effect on the relationship between market incentives and willingness to sort and recycle waste between males and females. The result of the structural model for moderation analysis in the above shows that the effect of social influence on households' willingness to sort and recycle waste was moderated by gender (male $(\beta=-0.178, p=0.000)$ and female $(\beta=0.708, p=0.041))$. Thus, this association was supported. Additionally, this indicates that the regression path between government facilitators and willingness to sort and recycle waste was not moderated by gender (male $(\beta=0.086, p=0.048)$ and female $(\beta=0.778$, $p=0.003)$ ). Therefore, this association was not supported.

The results can be practically applied to the residential community of Dammam, especially in the presence of positive awareness and attitudes that contribute in two respects. The first is the usefulness of sorting and recycling according to the income of the individuals and increasing income levels to facilitate the application of environmental services to maintain a healthy environment. The second is the participation of the residents in the sorting and recycling of waste, which represents a joint cooperation between the governmental authorities and the residents, and, of course, it may be applicable in all Saudi Arabian cities, but we may face a lack of the application of the study in the event that negative awareness appears in a resident's community; a further reason may also be the 
lack of understanding and a desire to benefit from the sorting and recycling of sustainable solid waste.

Overall, although this research was effective in explaining households' willingness to sort and recycle waste, several limitations exist. This study used only latent variables in the structural equation modelling (SEM) analysis, with income and gender as moderators. Future studies should include observable variables, such as age and marital status, in the SEM analysis to determine their contributions in predicting households' willingness to sort and recycle waste. Moreover, future studies should investigate the willingness for waste sorting and recycling from other sources of MSW, such as commercial and industrial organizations and offices. Consequently, the willingness to sort and recycle waste in different sectors would be understood, and appropriate policies could be formulated and implemented.

Author Contributions: O.L.-study conception and design, data collection and surveying, preparation of the draft manuscript and responsible for the manuscript submission. L.M.-supervision and reviewing the manuscript draft and make editing and a participant in final approval of the manuscript. A.H.S. - analysis the data, interpretation the results and contributed in reviewing the results and discussion section. S.S.M.Z.- supervision and review the data collection and analysis and also, contributed in final manuscript writing. All authors have read and agreed to the published version of the manuscript.

Funding: This research received no external funding.

Institutional Review Board Statement: Not Applicable.

Informed Consent Statement: Not Applicable.

Data Availability Statement: Available from the authors.

Acknowledgments: We full thanks the all in different organizations such as Central Agency for Statistics and Mobilization for completing the data collection, Eastern Province Municipality for helping to interviwing with residents of Dammam city and finally we thanks Ddepartment of Geography, College of Art, Imam Abdul Rahman bin Faisal University to ally support this study in publication in the journal.

Conflicts of Interest: The authors declare no conflict of interest.

\section{References}

1. Burnley, S.J.; Ellis, J.C.; Flowerdew, R.; Poll, A.J.; Prosser, H. Assessing the composition of municipal solid waste in Wales. Resour. Conserv. Recycl. 2007, 49, 264-283. [CrossRef]

2. Nabegu, A.B. An analysis of municipal solid waste in Kano metropolis, Nigeria. J. Hum. Ecol. 2010, 31, 111-119. [CrossRef]

3. Nguyen, P.T.; Yasuhiro, M.; Takeshi, F. Assessment of plastic waste generation and its potential recycling of household solid waste in Vietnam. Environ. Monit. Assess. 2011, 175, $23-35$.

4. Okot-Okumu, J. Solid Waste Management in African Cities-East Africa. In Waste Management-An Integrated Vision; InTech; Africa cties 2012; ISBN 978-953-51-0795-8. Available online: http:/ /www.intechopen.com/books/wastemanagement-an-integratedvision/solid-waste-management-in-african-citieseast-africa (accessed on 26 October 2012). [CrossRef]

5. Klöckner, C. A comprehensive model of the psychology of environmental behaviour-A meta-analysis. Glob. Environ. Chang. 2013, 23, 1028-1038. [CrossRef]

6. Hoornweg, D.; Bhada-Tata, P. What a Waste: A Global Review of Solid Waste Management; Urban Development Series; Papers No. 15; World Bank: Washington, DC, USA, 2012.

7. Zafar, S. Waste Management in Jeddah. 2015. Available online: http://www.ecomena.org/tag/solid-waste-management-injeddah/ (accessed on 27 February 2020).

8. Karim Ghani, W.A.; Rusli, I.F.; Biak, D.R.A.; Idris, A. An application of the theory of planned behaviour to study the influencing factors of participation in source separation of food waste. Waste Manag. 2013, 33, 1276-1281. [CrossRef]

9. Zhang, H.; Wen, Z.G. Residents' Household Solid Waste (HSW) Source Separation Activity: A Case Study of Suzhou, China. Sustainability 2014, 6, 6446-6466. [CrossRef]

10. Zhang, D.; Huang, G.; Yin, X.; Gong, Q. Residents' Waste Separation Behaviors at the Source: Using SEM with the Theory of Planned Behavior in Guangzhou, China. Int. J. Environ. Res. Public Health 2015, 12, 9475-9491. [CrossRef]

11. Xu, L.; Ling, L.; Lu, Y.; Shen, M. External influences on forming residents' waste separation behaviour: Evidence from households in Hangzhou, China. Habitat Int. 2017, 63, 21-33. [CrossRef] 
12. Henry, L.K.; Field, J.R.; Adkins, E.M.; Parnas, M.L.; Vaughan, R.A.; Zou, M.F.; Newman, A.H.; Blakely, R.D. Tyr-95 and Ile172 in trans-membrane segments 1 and 3 of human serotonin transporters interact to establish high affinity recognition of antidepressants. J. Biol. Chem. 2006, 281, 2012-2023. [CrossRef]

13. Memon, M.A. Integrated solid waste management based on the 3R approach. J. Mater. Cycles Waste Manag. 2010, 12, 30-40. [CrossRef]

14. Hornik, J.; Joseph, C.; Mandansky, M.; Narayana, C. Determinant of recycling behaviour: A synthesis of research result. J. Socio-Econ. 2005, 24, 105-127. [CrossRef]

15. Boldero, J. The prediction of household recycling of newspapers: The role of attitudes, intentions and situational factors. J. Appl. Soc. Psychol. 1995, 25, 440-462. [CrossRef]

16. Jones, R.E. An Integrated Model of Waste Management Behavior: A Test of Household Recycling and Composting Intentions. Sage J. Environ. Behav. 1995, 27, 603-630.

17. Laurence, H. End-of-life and waste management in life cycle assessment. Int. J. Life Cycle Assess. 2011, 17, 504-510.

18. Nguyen, T.T.P.; Zhu, D.; Le, N.P. Factors influencing waste separation intention of residential households in a developing country: Evidence from Hanoi, Vietnam. Habitat Int. 2015, 48, 169-176. [CrossRef]

19. Echevarría, C.A.; Idígoras, I.; Vicente-Molina, M.A. Gender issues related to choosing the successor in the family business. Eur. J. Fam. Bus. 2017, 7, 54-64. [CrossRef]

20. Chen, M.; Tung, P. The moderating effect of perceived lack of facilities on consumers recycling intentions. Environ. Behav. 2010, 42, 824-844. [CrossRef]

21. Carrus, G.; Passafaro, P.; Bonnes, M. Emotions, habits and rational choices in ecological behaviours: The case of recycling and use of public transportation. J. Environ. Psychol. 2008, 28, 51-62. [CrossRef]

22. Swami, V.; Coles, R.; Stieger, S.; Pietschnig, J.; Furnham, A.; Rehim, S.; Voracek, M. Conspiracist ideation in Britain and Austria: Evidence of a monological belief system and associations between individual psychological differences and real-world and fictitious conspiracy theories. Br. J. Psychol. 2011, 102, 443-463. [CrossRef]

23. Bortoleto, A.P.; Kurisu, K.H.; Hanaki, K. Model development for household waste prevention behaviour. Waste Manag. 2012, 32, 2195-2207. [CrossRef] [PubMed]

24. McDonald, F.V. Developing an Integrated Conceptual Framework of Pro-Environmental Behaviour in the Workplace through Synthesis of the Current Literature. Adm. Sci. 2014, 4, 276-303. [CrossRef]

25. Izagirre-Olaizola, J.; Fernandez-Sainz, A.; Vicente-Molina, M.A. Internal determinants of recycling behaviour by university students: A cross-country comparative analysis. Int. J. Consum. Stud. 2015, 39, 25-34. [CrossRef]

26. Wang, S.; Li, J.; Zhao, D. The impact of policy measures on consumer intention to adopt electric vehicles: Evidence from China. Transp. Res. Part A Policy Pract. 2017, 105, 14-26. [CrossRef]

27. Anjum, M.; Miandad, R.; Waqas, M.; Ahmad, I.; Alafif, Z.O.A.; Aburiazaiza, A.S.; Barakat, M.A.E.; Akhtar, T. Solid waste Management in Saudi Arabia. J. Sci. Food Agric. 2016, 1, 13-26.

28. Nguyen, L.T.; Zeng, M.; Tague, P.; Zhang, J. Recognizing new activities with limited training data. In Proceedings of the 2015 ACM International Symposium on Wearable Computers, Osaka, Japan, 7-11 September 2015; pp. 67-74.

29. Abdul-Aziz, H.; Isa, M.H.; Kadir, O.A.; Nordin, N.M.; Daud, W.R.W.; Alsebaei, A.F.; Abu-Rizaiza, A.S. Study of Baseline Data Regarding Solid Waste Management in the Holy City of Makkah during Hajj. The Custodian of the Two Holy Mosques Institute of the Hajj Research (Unpunished Report); Solid Waste Management in Saudi Arabia. A Review. Available online: https://www. researchgate.net/publication/316645642_Solid_Waste_management_in_Saudi_Arabia_A_review\#fullTextFileContent (accessed on 5 October 2007).

30. Sharma, B.K.; Moser, B.R.; Vermillion, K.E.; Doll, K.M.; Rajagopalan, N. Production, characterization and fuel properties of alternative diesel fuel from pyrolysis of waste plastic grocery bags. Fuel Process. Technol. 2014, 122, 79-90. [CrossRef]

31. Demirbas, A.; Alamoudı, R.H.; Ahmad, W.; Sheıkh, M.H. Optimization of municipal solid waste (MSW) disposal in Saudi Arabia. Energy Sources Part A Recover. Util. Environ. Eff. 2016, 38, 1929-1937. [CrossRef]

32. Aron, A. Online Dating: The Current Status-And Beyond. Psychol. Sci. Public Interest 2012, 13, 1-2. [CrossRef]

33. The World Bank. Saudi Arabia. 2015. Available online: https://data.worldbank.org/country/saudi-arabia (accessed on 16 November 2020).

34. Al-Sabahi, E.; Rahim, S.A.; Wan Zuhairi, W.Y.; Al-Nozaily, F.; Alshaebi, F. The Characteristics of Leachate and Groundwater Pollution at Municipal Solid Waste Landfill of Ibb City, Yemen. Am. J. Environ. Sci. 2009, 5, 230-240.

35. Hayes, R.C.; Dear, B.S.; Li, G.D.; Virgona, J.M.; Conyers, M.K.; Hackney, B.F.; Tidd, J. Perennial pastures for recharge control in temperate drought-prone environments. Part 1: Productivity, persistence and herbage quality of key species. N. Z. J. Agric. Res. 2010, 53, 283-302. [CrossRef]

36. Chen, X.; Geng, Y.; Fujita, T. An overview of municipal solid waste management in China. Waste Manag. 2010, 30, 716-724. [CrossRef]

37. Fisher, C.; Bashyal, S.; Bachman, B. Demographic impacts on environmentally friendly purchase behaviors. J. Target. Meas. Anal. Mark. 2012, 20, 172-184. [CrossRef]

38. Ajzen, I.; Fishbein, M. The influence of attitudes on behavior. In The Handbook of Attitudes; Albarracin, D., Johnson, B.T., Zanna, M.P., Eds.; Psychology Press: New York, NY, USA, 2005; pp. 173-221. 
39. Straughan, R.D.; Roberts, J.A.; Straughan, R.D.; Roberts, J.A. Environmental segmentation alternatives: A look at green consumer behavior in the new millennium. J. Consum. Mark. 1999, 16, 558-575. [CrossRef]

40. Meyer, R.; Liebe, U. Are the affluent prepared to pay for the planet? Explaining willingness to pay for public and quasi-private environmental goods in Switzerland. Popul. Environ. 2010, 32, 42-65. [CrossRef]

41. Do Paco, A.; Raposo, M. 'Green' segmentation: An application to the Portuguese consumer market. Mark. Intell. Plan. 2009, 27, 364-379. [CrossRef]

42. Bamberg, S.; Möser, G. Twenty years after Hines, Hungerford, and Tomera: A new meta-analysis of psycho-social determinants of pro-environmental behaviour. J. Environ. Psychol. 2007, 27, 14-25. [CrossRef]

43. Schultz, P.; Oskamp, S.; Mainieri, T. Who recycles and when? A review of personal and situational factors. J. Environ. Psychol. 1995, 15, 105-121. [CrossRef]

44. Rahman, S.M.; Khondaker, A. Mitigation measures to reduce greenhouse gas emissions and enhance carbon capture and storage in Saudi Arabia. Renew. Sustain. Energy Rev. 2012, 16, 2446-2460. [CrossRef]

45. Han, Y.; Hansen, H. Determinants of Sustainable Food Consumption: A Meta-Analysis Using a Traditional and a Structura Equation Modelling Approach. Int. J. Psychol. Stud. 2012, 4, 22-46. [CrossRef]

46. Kumar, B. Theory of Planned Behavior Approach to Understand the Purchasing Behavior for Environmentally Sustainable Products. Indian Inst. Manag. 2012. Available online: http://vslir.iima.ac.in:8080/jspui/handle/11718/11429 (accessed on 6 April 2020).

47. Lei, C.F.; Ngai, E.W.T. A Research Agenda on Managerial Intention to Green It Adoption: From Norm Activation Perspective. PACIS 2014 Proceedings. 2014. Available online: https: / / aisel.aisnet.org/cgi/viewcontent.cgi?article=1147\&context=pacis2014 (accessed on 26 November 2020).

48. Pakpour, A.H.; Zeidi, I.M.; Emamjomeh, M.M.; Asefzadeh, S.; Pearson, H. Household waste behaviors among a community sample in Iran: An application of the Theory of Planned Behavior. Waste Manag. 2014, 34, 980-986. [CrossRef] [PubMed]

49. Botetzagias, I.; Dima, A.F.; Malesios, C. Extending the Theory of Planned Behavior in the context of recycling: The role of moral norms and of demographic predictors. Resour. Conserv. Recycl. 2015, 95, 58-67. [CrossRef]

50. Agabalinda, C.; Isoh, V.N. Moderating effects of social learning on the usage of formal financial services in Kampala, Uganda. J. Econ. Int. Financ. 2020, 12, 120-129.

51. Byrne, B.M. Structural Equation Modeling with AMOS: Basic Concepts, Applications, and Programming, 2nd ed.; Multivariate Applications Series, 2nd Edition; Routledge: New York, NY, USA, 2009.

52. Browne, M.W.; Cudeck, R. Single sample across: Validation indices for covariance structures. Multivar. Behav. Res. 1989, 24, 445-455. [CrossRef] [PubMed]

53. Hair, J.F.; Black, W.C.; Babin, B.J.; Anderson, R.E. Multivariate Data Analysis: A Global Perspective, 7th ed.; Pearson Prentice Hall: Upper Saddle River, NJ, USA, 2010.

54. Samah, B.A. Enhancing Extention Education Research Using Structural Equation Modelling, 1st ed.; University Putra Malaysia Press: Serdang, Malaysia, 2016.

55. MacCoun, R.J. Biases in the Interpretation and Use of Research Results. Annu. Rev. Psychol. 1998, 49, 259-287. [CrossRef]

56. Stern, P.C.; Abel, T.; Guagnano, G.A.; Kalof, L. A value-belief-norm theory of support for social movements: The case of environmentalism. Res. Hum. Ecol. 1999, 6, 81-97.

57. Davies, J.; Foxall, G.R.; Pallister, J. Beyond the intention-behaviour mythology: An integrated model of recycling. Mark. Theory 2002, 2, 29-113. [CrossRef]

58. Tonglet, M.; Phillips, P.S.; Read, A.D. Using the Theory of Planned Behaviour to investigate the determinants of recycling behaviour: A case study from Brixworth, UK. Resour. Conserv. Recycl. 2004, 41, 191-214. [CrossRef]

59. Gamba, R.J.; Oskamp, S. Factors influencing community residents' participation in commingled curbside recycling programs. Environ. Behav. 1994, 26, 587-612. [CrossRef] 